\title{
Applying philosophy, logic, and rational argumentation to the Severe Acute Respiratory Syndrome Coronavirus- 2 pandemic response
}

Authors: Ari R Joffe ${ }^{1}$, David Redman ${ }^{2}$

Affiliations: 1. Department of Pediatrics, Division of Pediatric Critical Care, and John Dossetor Health Ethics Center, University of Alberta, Edmonton, Alberta, Canada. 2. Retired LCol, Former head of Alberta Emergency Management Agency, Edmonton, Alberta, Canada.

Corresponding Author: Ari R Joffe MD; 4-546 Edmonton Clinic Health Academy; 11405112 Street; Edmonton, Alberta, Canada; T6G 1C9. Email: ajoffe@ualberta.ca

\section{Abstract:}

Part of philosophy is to subject assertions to critical scrutiny, clarifying exactly what the assertion is saying, its implications, and thus its direct plausibility. The goal is to ensure clarity, logical consistency, and rational argumentation in order to arrive at reasoned conclusions. A common problem is that arguments have missing implied premises that, unless explicitly stated, are mistakenly assumed to be true. Here we subject conclusions made regarding the SARS-CoV-2 pandemic to critical scrutiny, revealing their implied premises so that these premises can be explicitly examined and refuted. Specifically, we refute the conclusions that "no one is protected until everyone is protected" and "population lockdowns are required to protect those at high risk of adverse outcomes." In the end, we argue for the conclusion that "an Emergency Management principles based response to the pandemic, compared to population-wide lockdowns, offers a way to prevent more adverse outcomes from COVID19 , better prevent overwhelmed healthcare, and prevent most of the collateral damage to the wellbeing of the population that has resulted from the lockdowns."

Keywords: COVID-19; critical scrutiny; logic; pandemic; response; SARS-CoV-2 
Part of philosophy is to subject assertions to critical scrutiny, clarifying exactly what the assertion is saying, its implications, and thus its direct plausibility. The goal is to ensure clarity, logical consistency, and rational argumentation in order to arrive at reasoned conclusions. ${ }^{1} \mathrm{~A}$ common problem is that arguments have missing implied premises that, unless explicitly stated, are mistakenly assumed to be true. Here we subject conclusions made regarding the SARS-CoV-2 pandemic to critical scrutiny, revealing their implied premises so that these premises can be explicitly examined and refuted.

\section{"No one is protected until everyone is protected."}

The Chief Public Health Officer of Canada has made the assertion that, regarding the response to the pandemic, "the bottom line [is that] no one is protected until everyone is protected. " 2 What this means is unclear, as the premises needed to draw this conclusion are missing. The premises implied in the report seem to be as follows:

(P1) SARS-CoV-2 can infect anyone of any age or demographic group.

(P2) SARS-CoV-2 infection can cause COVID-19 in anyone of any age or demographic group.

We accept these premises. Now we need to explicitly state why protection for everyone is required. One possibility is this:

(P3) COVID-19 in anyone of any age or demographic group can cause death.

(P4) Protection from this risk of death to anyone of any age or demographic group is required.

But there are still missing premises needed in order to draw the necessary conclusion and support the claim that this risk requires protection of all (P4), something like this:

(P5) This risk to anyone of any age or demographic is so high that protection of all must be a goal.

(P6) Similar risks to anyone of any age or demographic require protection of all.

But these premises are easy to refute. Regarding (P5), it is not the case that everyone is at similarly high risk. The risks of hospitalization, intensive care unit admission, and especially death are highly age dependent. There is an inflection point in the infection fatality rate curve at about the age of 70 years. ${ }^{3}$ The risk of infection fatality is lower than that from influenza each year in people under age 50 years. ${ }^{4}$ The risk of infection fatality in those age 60-69 years is highly dependent on underlying severe comorbidities, including obesity, diabetes, dementia, chronic kidney disease, and some others. ${ }^{5}$ In Canada, over the first year of the pandemic $88.4 \%$ of deaths occurred in people age 70 years or older, and in the first wave the relative risk of death for those under 65 years was 100-times lower than for those age 65

\footnotetext{
${ }^{1}$ Howard Nye, "Chapter 24: Directly plausible principles," in The Palgrave Handbook of Philosophical Methods, ed. Christopher Daly (London: Palgrave Macmillan, 2015), 610-636.

${ }^{2}$ Chief Public Health Officer of Canada, Report on the State of Public Health in Canada 2020. From Risk to

Resilience: An Equity Approach to COVID-19 (Ottawa: Public Health Agency of Canada, 2020), p.2

https://www.canada.ca/en/public-health/corporate/publications/chief-public-health-officer-reports-state-publichealth-canada/from-risk-resilience-equity-approach-covid-19.html

${ }^{3}$ John PA loannidis, "Infection fatality rate of COVID-19 inferred from seroprevalence data," Bulletin of the World Health Organization, 99 (2021): 19-33F; Andrew T Levin, et al., "Assessing the age specificity of infection fatality rates for COVID-19: systematic review, meta-analysis, and public policy implications," European Journal of Epidemiology, 35 (2020): 1123-1138; Megan O'Driscoll M, et al., "Age-specific mortality and immunity patterns of SARS-CoV-2," Nature, 590 (2021): 140-145; depressio

${ }^{4}$ Ari R Joffe, "COVID-19: Rethinking the Lockdown Groupthink," Frontiers in Public Health 9 (2021): 625778.

${ }^{5}$ Elizabeth J Williamson, et al., "Factors associated with COVID-19-related death using OpenSAFELY," Nature 548, (2020): 430-436.
} 
and older. ${ }^{6}$ Regarding (P6), globally, COVID-19 over the first year was associated with about $4.1 \%$ of deaths, while motor vehicle collisions, alcohol use, tobacco use, fossil fuel combustion fine particulate matter pollution, and poor diet accounted for $2.3 \%, 5.1 \%, 13.7 \%, 14.9 \%$, and $18.8 \%$ of deaths respectively. ${ }^{7}$ We don't close down society in order to protect everyone from these prevalent causes of death. In fact, we accept those risks in order to exercise our Charter freedoms.

Maybe the premises need to be modified. We can replace the risk we are talking about with "longCOVID" instead of "death". Some claim that $10 \%$ of people having had SARS-CoV-2 infection will have long-term symptoms of severe fatigue, breathlessness, and chronic heart disease. Consider these premises:

(P3') SARS-CoV-2 infection in anyone of any age or demographic group can cause long-COVID.

(P4') Protection from this risk of long-COVID in anyone of any age or demographic group is required.

Again, we require more premises to support the claim in (P4') that protection is required, that is, we still need (P5) and (P6). But (P5) and (P6) can again be refuted. Regarding (P5), the incidence, severity, and duration of long-COVID are not known. Studies to date do not well quantify the severity and duration of long-term symptoms such as fatigue, breathlessness, 'foggy thinking', etc., making it difficult to interpret the actual impact. The highest rates of long-COVID are from crowdsourced online data where there is likely a strong participant selection bias. A recent large study found that app users who had detected COVID-19 cases reported symptoms (of unknown severity) at $\geq 8$ weeks in $4.5 \%$ and at $\geq 12$ weeks in $2.3 \%$ (of whom $43.9 \%$ had been hospitalized). ${ }^{8} \mathrm{~A}$ recent review suggested that around $30 \%$ of hospitalized COVID-19 cases have post-acute COVID-19 syndrome (of unclear severity) ${ }^{9}$; generously, this would mean that if $<5 \%$ of cases are hospitalized, then $<1 \%$ of infections are hospitalized (the number of infections for each detected case is usually up to 10 -times higher), ${ }^{10}$ and if $30 \%$ of these have post-acute COVID-19, then at most $0.3 \%$ of infections end up with this syndrome. Most reports of cohorts with long-COVID do not compare to contemporary controls during the pandemic, controls who are often (in about $30 \%$ of people) experiencing social isolation, unemployment, loneliness, and anxiety or depression. ${ }^{11}$ Moreover, nocebo effects due to constant bombardment with reports of deaths and long-COVID in the press and

\footnotetext{
${ }^{6}$ Government of Canada, "Coronavirus Disease 2019 (COVID-19): Epidemiology Update" 2021, accessed March 5, 2021, https://health-infobase.canada.ca/covid-19/epidemiological-summary-covid-19-cases.html; John PA Ioannidis, Cathrine Axfors, Despina G Contopoulos-loannidis, "Population-level COVID-19 mortality risk for nonelderly individuals overall and for non-elderly individuals without underlying disease in pandemic epicenters," Environmental Research 188 (2020): 109890. https://doi.org/10.1016/i.envres.2020.109890 .

7 Joffe, "Rethinking," 625778; Karn Vohra, et al., "Global mortality from outdoor fine particulate pollution generated by fossil fuel combustion: Results from GEOS-Chem," Environmental Research, 195 (2021): 110754.

${ }^{8}$ Carole H Sudre, et al., "Attributes and predictors of long COVID," Nature Medicine 2021. https://doi.org/10.1038/s41591-021-01292-y.

${ }^{9}$ Ani Nalbandian, et al., "Post-acute COVID-19 syndrome," Nature Medicine 2021. https://doi.org/10.1038/s41591$\underline{021-01283-z}$

${ }^{10}$ Ioannidis, "Infection fatality rate," 19-33F; loanndis, "Reconciling estimates"; Levin et al., "Assessing the age specificity," 1123-1138.

${ }^{11}$ Mark E Czeisler, et al., "Follow-up survey of US adult reports of mental health, substance use, and suicidal ideation during the COVID-19 pandemic, September 2020," Journal of the American Medical Association Network Open 4, no. 2 (2021): e2037665; Nader Salari, et al., "Prevalence of stress, anxiety, depression among the general population during the COVID-19 pandemic: a systematic review and meta-analysis," Globalization and Health 16 (2021): 57.
} 
on social media, creating anxiety, fear, and negative expectations, may lead to at least some of the cases. $^{12}$

Overall, the likelihood of long-COVID symptoms of high severity and duration in people infected with SARS-CoV-2 (most of whom are either asymptomatic or mildly symptomatic, not requiring hospitalization) is not known, and likely low. Regarding (P6), it seems that the effects of motor vehicle collisions, alcohol use, tobacco use, and poor diet in causing severe disability from trauma, stroke, myocardial infarction, heart failure, and other sequelae must be far higher than that from long-COVID. Yet, we don't close down society in order to protect everyone from these long-term sequelae.

We can modify the premises again. We can replace the risk we are talking about with "overwhelmed healthcare capacity."

(P3") SARS-CoV-2 infection in anyone of any age or demographic group can cause overwhelmed healthcare capacity.

(P4") Protection from this risk of overwhelmed healthcare capacity in anyone of any age or demographic is required.

Once again, we still require (P5) and (P6), and these can again be refuted. Regarding (P5), the risk is highly age dependent, with most hospitalizations being in older people, and not children or young adults. Much of the risk is theoretical and based on forecasting (modeling); yet, forecasting of healthcare capacity needs for COVID-19 in the short or medium term has consistently failed, even when built directly on data for next day predictions. ${ }^{13}$ Most healthcare systems were not overwhelmed, including in non-locked-down Sweden, despite sometimes being stressed with high peaks of cases. ${ }^{14} \mathrm{We}$ have more to say about this below in discussing premise (MP3). Regarding (P6), hospitals in many higher income countries are routinely over-capacity every winter viral season. ${ }^{15}$ Yet, we don't close down society in order to protect everyone from over-capacity hospitals. We accept the risk in order to maintain our Charter freedoms.

Overall, we believe the conclusion that "no one is protected until everyone is protected" is not supportable by premises that survive critical scrutiny. Nevertheless, we accept that protection of those at high risk of adverse outcomes is warranted, particularly those age 70 years or older (with infection fatality rate rising above $2 \%$ at this age, and higher as age increases), and those age 60-69 years with multiple severe co-morbidities. Many of these people reside in long-term-care facilities, where infection

\footnotetext{
${ }_{12}$ Philipp Bagus, Jose Antonio Pena-Ramos, and Antonio Sanchez-Bayon, "COVID-19 and the political economy of mass hysteria," International Journal of Environmental Research and Public Health, 18, no. 4 (2021): 1376.

${ }^{13}$ John PA Ioannidis, Sally Cripps, and Martin A Tanner, "Forecasting for COVID-19 has failed," International Journal of Forecasting, 2021. https://doi.org/10.1016/i.ijforecast.2020.08.004.

${ }^{14}$ Ioannidis et al., "Forecasting"; Jasmine M Gardner, et al., "Intervention strategies against COVID-19 and their estimated impact on Swedish healthcare capacity," medRxiv, April 15, 2020. DOI:

https://doi.org/10.1101/2020.04.11.20062133 predicted "under conservative epidemiological parameter estimates" that the need for intensive care beds would be at least 40 -fold greater than pre-pandemic capacity and at least 96,000 deaths would occur by 1 July 2020 without mitigation; Andrius Kavaliunas, et al., "Swedish policy analysis for Covid-19," Health Policy and Technology (2020) 9: 598-612 showed that by August 13, 2020 the number of deaths had been 5776, and the intensive care units were not overwhelmed.

${ }^{15}$ The winter NHS narrative: The Guardian. https://i.redd.it/ful7xgey1hg61.jpg; Shawn Whatley, "COVID and health-care capacity: New symptom, old problem," iPOLITICS (Jan 28, 2021) https://ipolitics.ca/2021/01/28/covidand-health-care-capacity-new-symptom-old-problem/; Carlo Caduff, "What went wrong: Corona and the World after the full stop," Medical Anthropology Quarterly, 34, no. 4 (2020): 467-487.
} 
fatality rate can rise to over $20 \%$. Older people in the population, particularly those with co-morbidities, are those who are at high risk of adverse outcomes from SARS-CoV-2 infection. There is another question to address: could it be the case that these people at high risk cannot be protected unless everyone is protected?

"Population-wide lockdowns are required to protect those at high risk of adverse outcomes" Population-wide lockdowns of combinations of many non-pharmaceutical interventions to "flatten the curve" of cases and deaths from COVID-19 were implemented in most countries, often in close succession of each other. ${ }^{16}$ The conclusion that these population-wide lockdowns were and still are required seems to be based on several implied premises.

(PL1) Lockdowns are highly effective at preventing the spread of SARS-CoV-2, reducing case and death rates.

(PL2) Lockdowns will therefore have a favorable cost-benefit balance.

(PL3) Lockdowns are the only highly effective way to prevent the spread of SARS-CoV-2, reducing case and death rates.

(PL4) Both reducing case rates and death rates must be the goal.

The problem is that each of these premises is false. Let us examine them one by one.

(PL1) Lockdowns are highly effective at preventing the spread of SARS-CoV-2, reducing case and death rates.

This premise has been assumed, and some studies have supported the assertion with various modeling assumptions. ${ }^{17}$ Part of the assumption is based on mistaking correlation for causation, with people observing waves of cases declining coincident with implementation of lockdowns in their own location. However, there are many studies that find the efficacy of lockdown non-pharmaceutical interventions to prevent the spread of SARS-CoV-2 are not at all clear. When comparing between country and state lockdown stringency and their COVID-19 case and death rates, while controlling for confounding factors such as population age distribution and density, life-expectancy trajectories, comorbidity prevalence, time from first COVID-19 death to lockdown, and other variables, there is no clear relationship. ${ }^{18}$ It is most likely that the efficacy of lockdowns has at the very least been highly exaggerated.

\footnotetext{
${ }^{16}$ Abiel Sebhatu, et al., "Explaining the homogeneous diffusion of COVID-19 nonpharmaceutical interventions across heterogeneous countries," Proceedings of the National Academy of Sciences of the United States of America, 117, no. 35 (2020): 21201-21208; Martin Lally, "The costs and benefits of COVID-19 lockdowns in Australia," (8 February 2020) https://clubtroppo.com.au/files/2021/04/THE-COSTS-AND-BENEFITS-OF-A-COVIDLOCKDOWN-6.pdf, page 36.

${ }^{17}$ Seth Flaxman, et al., "Estimating the effects of non-pharmaceutical interventions on COVID-19 in Europe," Nature 284 (2020):257-261. This model has been criticized for using circular reasoning; using the same data others found lockdowns had no or little effect, see: Vincent Chin, et al., "Effects of non-pharmaceutical interventions on COVID-19: a tale of three models," medRxiv (2020). https://doi.org/10.1101/2020.07.22.20160341; Christof Kuhbandner, and Stefan Homburg, "Commentary: estimating the effects of nonpharmaceutical interventions on COVID-19 in Europe," Frontiers in Medicine, 7 (2020):580361.

${ }^{18}$ Eran Bendavid, et al., "Assessing mandatory stay-at-home and business closure effects on the spread of COVID19," European Journal of Clinical Investigation, 2021 https://doi.org/10.1111/eci.13484; Rabail Chaudhry, et al., "A country level analysis measuring the impact of government actions, country preparedness and socioeconomic factors on COVID-19 mortality and related health outcomes," EClinicalMedicine, 25 (2020): 100464; Chin, et al., "Effects of non-pharmaceutical interventions"; Quentin De Larochelambert, et al., "Covid-19 mortality: A matter of vulnerability among nations facing limited margins of adaptation," Frontiers in Public Health 8 (2020): 604339;
} 
There are several possible explanations that make lack of lockdown efficacy plausible. For one, most people will take actions tailored to their own acceptable level of risk (and while continuing to carry out their essential activities) making the incremental effect of lockdowns very limited. ${ }^{19}$ For another, in the attempt to avert infections inside a system, lockdown restrictions in fact create forced congestion (and hence transmission) in other parts of the system. ${ }^{20}$ For example, congestion in lineups for access to grocery stores, in lineups for screening at healthcare centers and vaccination clinics, and in households where young people returned to live with their older parents and grandparents (due to unemployment or school/university closures). ${ }^{21}$ Finally, it is interesting that one of the strongest risk factors for COVID19 hospitalization, admission to intensive care, and mortality has been physical inactivity, being a stronger risk factor than severe obesity, cardiovascular disease, chronic lung disease, chronic kidney disease, diabetes, or metastatic cancer. "Regular physical activity may be the single most important action individuals can take to prevent severe COVID-19 and its complications." 22 Yet, lockdowns directly cause inactivity, and therefore may directly cause higher rates of severe COVID-19.

\section{(PL2) Lockdowns will therefore have a favorable cost-benefit balance.}

This premise has not usually been critically examined by those who have imposed lockdowns. In order to impose restrictions on Charter freedoms it is necessary to perform due diligence, that is, to demonstrate that lockdowns confer more benefit than harm. ${ }^{23}$ There are many predictable and devastating costs of lockdowns that seem to not have been considered. Costs include those from school closures, disrupted healthcare, intimate partner violence, deteriorating mental health, loneliness, unemployment, adverse childhood experiences, and worsened societal inequality. ${ }^{24}$ Loneliness, unemployment, and adverse childhood experiences are among the strongest risk factors for early mortality, shortened lifespan, and development of non-communicable chronic diseases. ${ }^{25}$ Missing education has effects into adulthood on intelligence, teen pregnancy, illicit drug use, graduation rates, employment rates and earnings, arrest

\footnotetext{
Savaris RF, et al., "Stay-at-home policy is a case of exception fallacy: an internet-based ecological study," Scientific Reports 11 (2021): 5313; Christopher T Leffler, et al., "Association of country-wide Coronavirus mortality with demographics, testing, lockdowns, and public wearing of masks," American Journal of Tropical Medicine and Hygiene, 103, no. 6 (2020): 2400-2411; John Gibson, “Government mandated lockdowns do not reduce Covid-19 deaths: implications for evaluating the stringent New Zealand response," New Zealand Economic Papers, (2020). https://doi.org/10.1080/00779954.2020.1844786; John Gibson, “Hard, not early: putting the New Zealand Covid19 response in context," New Zealand Economic Pa) https://doi.org/10.1080/00779954.2020.1842796; W Allen, "Covid lockdown cost/benefits: a critical assessment of the literature," (April 2021) Simon Fraser University www.sfu.ca/ allen/LockdownReport.pdf; Lally, "Costs and Benefits in Australia"; Kuhbandner and Homburg, "Commentary: estimating the effects."

${ }^{19}$ Allen, "Covid lockdown cost/benefits"; Lally, "Costs and Benefits in Australia."

20 Paul Frijters, "Covid-congestion effects: why are lockdowns so deadly?" Club Troppo (2021) https://clubtroppo.com.au/2021/02/03/covid-congestion-effects-why-are-lockdowns-so-deadly/.

${ }^{21}$ Frijters, "Covid-congestion effects"; Lally, "Costs and Benefits in Australia."

${ }^{22}$ Roberta Sallis, et al., "Physical inactivity is associated with a higher risk for severe COVID-19 outcomes: a study in 48440 adult patients," British Journal of Sports Medicine, (2021) https://doi.org/10.1136/bjsports-2021-104080, page 7 .

${ }^{23}$ Justice Center for Constitutional Freedoms (JCCF), Flying Blind: Government's hasty decisions to lock down Canadians while damaging public health and the economy (2020). https://www.jccf.ca/published reports/flyingblind-governments-hasty-decisions-to-lock-down-canadians-while-damaging-public-health-and-the-economy/ ${ }^{24}$ Joffe, "Rethinking," 625778.

${ }^{25}$ Noah Snyder-Mackler, et al., "Social determinants of health and survival in humans and other animals," Science, 368 (2020): eaax9553.
} 
rates, hypertension, diabetes, and depression. ${ }^{26}$ Missing school also causes food insecurity from missing school meals, loss of a place of safety, physical inactivity, lost support services for developmental difficulties, lost social interactions, and economic detriment to families from missed work. ${ }^{27}$ In higher income countries there has been a marked reduction in emergency visits for heart attacks and strokes, cancer screenings and diagnoses, and non-cancer surgeries, and increases in wait times for procedures, police reports and support line calls for domestic violence, opioid overdose deaths, alcohol consumption rates, tobacco smoking, suicidal thoughts, and depression and anxiety symptoms. ${ }^{28}$ The costs are particularly severe for disadvantaged populations, including in low- and middle-income countries where the sustainable development goals have been put out of reach. ${ }^{29}$ There are expected increases in the number of people living in extreme poverty by over 70 million, with food insecurity by over 83 million, having unsafe abortions by 2.7 million, having female genital mutilation and child marriages by over 2 million and 13 million over the next decade, children living in multidimensional poverty by 150 million, having death from tuberculosis, malaria, and HIV by hundreds of thousands, and missing vaccines for important infectious diseases for millions. ${ }^{30}$ The recession alone can be predicted to have higher cost than the benefits of lockdowns, even if lockdowns were to be highly effective. The argument about the effect of recession is as follows:

\footnotetext{
${ }^{26}$ Michael Silverman, Robert Sibbald, and Saverio Stranges, "Ethics of COVID-19- related school closures," Canadian Journal of Public Health, 111 (2020): 462-5; Dimitri A Christakis, Wil Van Cleve, Frederick J Zimmerman, "Estimation of US children's educational attainment and years of life lost associated with primary school closures during the Coronavirus Disease 2019 pandemic," JAMA Network Open (2020) 3(11): e2028786.

${ }^{27}$ Silverman, Sibbald, and Stranges, "Ethics," 462-465.

${ }^{28}$ Lisa Rosenbaum, "The untold toll - the pandemic's effects on patients without Covid-19," New England Journal of Medicine, 382 (2020): 2368-71; Matthew D Solomon, et al., "The COVID-19 pandemic and the incidence of acute myocardial infarction," New England Journal of Medicine, 383 (2020): 691-693; Sud A, et al., "Collateral damage: the impact on outcomes from cancer surgery of the COVID-19 pandemic," Annals of Oncology, 31 (2020): P106574; Harvey W Kaufman, et al., "Changes in the numbers of US patients with newly identified cancer before and during the coronavirus disease 2019 (COVID-19) pandemic," Journal of the American Medical Association Network Open, 3 (2020): e2017267; David R Urbach, and Danielle Martin, "Confronting the COVID-19 surgery crisis: time for transformational change," Canadian Medical Association Journal, 192 (2020): E585-586; John Z Ayanian, "Tallying the toll of excess deaths from COVID-19," Journal of the American Medical Association Health Forum, 1 (2020):e200832; Nori L Bradley, et al., "Health care practitioners' responsibility to address intimate partner violence related to the COVID-19 pandemic," Canadian Medical Association Journal, 192 (2020) :E609-10; Dominik A Moser DA, et al., "Years of life lost due to the psychosocial consequences of COVID-19 mitigation strategies based on Swiss data," European Psychiatry, 63 (2020): e58.

${ }^{29}$ Robin Naidoo, and Brendan Fisher, "Reset sustainable development goals for a pandemic world," Nature, 583 (2020): 198-201; The United Nations, The Sustainable Development Goals Report, (2020). https://unstats.un.org/sdgs/report/2020/TheSustainable-Development-Goals-Report-2020.pdf .

${ }^{30}$ FAO, IFAD, UNICEF, WFP, and WHO, The State of Food Security and Nutrition in the World 2020. Transforming Food Systems for Affordable Health Diets (Rome: FAO, 2020), 320 p.

http://www.fao.org/3/ca9692en/CA9692EN.pdf; David Laborde, et al., "COVID-19 risks to global food security," Science, 369 (2020):v500-2; World Health Organization, The Potential Impact of Health Service Disruptions on the Burden of Malaria: A Modelling Analysis for Countries in Sub-Saharan Africa (Geneva: World Health Organization, 2020) https://www.who.int/publications/i/item/9789240004641; Stop TB Partnership, The Potential Impact of the COVID-19 Response on Tuberculosis in High-Burden Countries: A Modelling Analysis (2020). http://www.stoptb.org/assets/documents/news/Modeling\%20Report 1\%20May\%202020 FINAL.pdf; Britta L Jewell, et al., "Potential effects of disruption to HIV programmes in sub-Saharan Africa caused by COVID-19: results from multiple mathematical models," Lancet HIV, 7 (2020): e629-40; UNFPA, Impact of the COVID-19 Pandemic on Family Planning and Ending Gender-Based Violence, Female Genital Mutilation and Child Marriage. Interim Technical Note (2020) https://www.unfpa.org/pcm/node/24179; Elizabeth Roesch, et al., "Violence against women during covid-19 pandemic restrictions," British Medical Journal, 360 (2020): m1712.
} 
Rational Argumentation and Pandemic Response

(PL2P1) The wellbeing of the population is the ultimate goal of government: the goal is to maximize the sum of years lived by the population, weighted by the wellbeing quality (life satisfaction) of those years. ${ }^{31}$

(PL2P2) Government spending on services determines the population wellbeing and life expectancy: spending on healthcare, education, roads, transportation, sanitation, housing, nutrition, vaccines, safety, social security nets, clean energy, etc. ${ }^{32}$

(PL2P3) Lockdowns are a government public health policy: we should treat decisions on how to face COVID-19 in the same way as decisions are made about resources to apply to the treatment of cancer, diabetes, etc. At most, this cost is $\$ 80-100,000 / Q A L Y$, and a more realistic number is $\$ 30,000 /$ QALY. ${ }^{33}$

(C1) COVID-19 deaths vs. the economy is a dangerous false dichotomy: it is about COVID-19 deaths vs. economic recession caused deaths.

(C2) We need to choose the least harmful of terrible choices.

When one does the calculations, as several cost-benefit analyses have done, even only considering the recession effect finds that lockdowns cause far more (at least 10 times more) harm to population wellbeing than benefit. ${ }^{34}$ Some have considered some of the long list of collateral harms from lockdowns described above, also finding that lockdowns cause far more harm than benefit. ${ }^{35}$ When one considers that the efficacy of lockdowns has most likely been highly exaggerated, the balance becomes even more extreme against lockdowns.

(PL3) Lockdowns are the only highly effective way to prevent the spread of SARS-CoV-2, reducing case and death rates.

This premise has been surprisingly little subjected to critical scrutiny. Many have called for a more balanced focused approach. ${ }^{36}$ In fact, pre-pandemic plans did not call for lockdowns, and did not

\footnotetext{
${ }^{31}$ Paul Frijters, et al., "A happy choice: wellbeing as the goal of government," Behavioural Public Policy, 4 (2020): 126-65; Paul Frijters, and Christian Krekel, "Chapter 1: the case for wellbeing as the goal of government in the context of constraints on policy-making," in A Handbook for Wellbeing Policy-Making: History, Theory, Measurement, Implementation, and Examples, edited by Paul Frijters and Christian Krekel. London: Oxford University Press, 2020.

32 Paul Frijters, "On Corona/Covid-19, Herd Immunity, and WELLBY Tradeoffs - Key Predictions and Numbers," Club Troppo (2020). https://clubtroppo.com.au/2020/05/14/on-corona-covid-19-herdimmunity-and-wellby-tradeoffskey-predictions-and-numbers/.

${ }^{33}$ Frijters, "On Corona/Covid-19"; David Miles, Mike Stedman, and Adrian Heald, "Living with Covid-19: balancing costs against benefits in the face of the virus," National Institute Economic Review, 253 (2020): R60-76; Lally, "Costs and Benefits in Australia."

${ }^{34}$ Frijters, "On Corona/Covid-19"; Miles et al., "Living with Covid-19," R60-76; Joffe, "Rethinking," 625778; Gigi Foster, "Cost-Benefit Analysis Executive Summary. Presented to Victorian Parliament in Australia," (2020). https://parliament.vic.gov.au/images/stories/committees/paec/COVID-

19 Inquiry/Tabled Documents Round 2/CBA Covid Gigi Foster.pdf; Dave Heatley, "A Cost Benefit Analysis of 5 Extra Days at COVID-19 Alert Level 4. New Zealand Productivity Commission," (2020). https://www.productivity.govt.nz/research/cost-benefit-analysis-covid-alert-4/.

${ }^{35}$ Frijters, "On Corona/Covid-19"; Joffe, "Rethinking," 625778; Gigi Foster, "Cost-Benefit Analysis"; Lally, "Costs and Benefits in Australia"; Allen, "Covid lockdown cost/benefits."

${ }^{36}$ Robert Bell, et al., "Dealing With COVID-19: an Open Letter to Canada's Prime Minister and Provincial and Territorial Premiers,"(2020) https://healthydebate.ca/opinions/an-open-letter-to-pm-covid19; Campbell Newman, et al., “Open Up Our Country - Sign the Open Letter: To The National Cabinet, (2020).

https://aip.asn.au/2020/06/open-up-our-country-sign-the-open-letter/; Edward R Melnick, and John PA loannidis, "Should governments continue lockdown to slow the spread of covid-19?," British Medical Journal, 369 (2020):
} 
recommend them. This is true for reviews written by experts at the Centers for Disease Control in the United States, and the World Health Organization as recently as 2019. ${ }^{37}$

We believe that the pandemic is better framed as a public emergency, not a public health emergency, affecting all sectors of society. This means that the process of emergency management (EM) is a better and highly effective way to respond, aiming to minimize the impact of SARS-CoV-2 on our society as a whole. ${ }^{38}$ A coordinating EM agency should coordinate requests from the Subject Matter Agency [public health] dealing with the direct effects of the virus, while also dealing with the indirect effects of the pandemic. Response plans should address not just one goal [controlling the spread of infection and reducing illness and death from the virus], but three others as well, including mitigating societal disruption by ensuring continuity and recovery of critical services, minimizing adverse economic impact, and supporting an efficient and effective use of resources. ${ }^{39}$ Using EM principles, better priorities are clear.

First, protect those most at risk by separating them from the threat. Residents and staff of long-termcare homes should be placed in quarantine, with volunteer staff asked to work one-month-on and onemonth-off living away from their families with generous compensation. This may be done in new larger facilities to reduce staffing demands. Seniors in the community with multiple severe co-morbidities require voluntary quarantine, either with plans for separate housing in temporary long-term-care-like facilities, or in-home quarantine with voluntary caregivers. This would prevent most deaths and challenges to hospital capacity, without lockdown of all of society.

Second, ensure critical infrastructure is ready for people who get sick. Building new surge capacity in hospitals, without cancelling or delaying healthcare for diseases other than COVID-19, is required. Asymptomatic healthcare workers (even exposed or SARS-CoV-2 swab positive) can continue to work in hospitals with universal staff masking policies to preserve the workforce. ${ }^{40}$ Not closing schools will also help preserve over $15 \%$ of the healthcare workforce from having to stay home with their children. ${ }^{41}$

m1924; Sanjeev Sabhlok, "Why I Quit Rather Than Be Silenced: Vic Treasury Insider, Financial Review (2020). https://www.afr.com/policy/economy/victoria-has-locked-itself-into-a-lockdown-blunder-20200916-p55w1z; Martin Kullforff, Sunetra Gupta, and Jay Bhattacharya, "Great Barrington Declaration," (2020).

https://gbdeclaration.org/.

${ }^{37}$ World Health Organization, Non-pharmaceutical Public Health Measures for Mitigating the Risk and Impact of Epidemic and Pandemic Influenza, (2019)

https://www.who.int/influenza/publications/public health measures/publication/en/; Thomas V Inglesby, et al., "Disease mitigation measures in the control of pandemic influenza," Biosecurity and Bioterrorism, 4, no. 4 (2006):366-375.

${ }^{38}$ David Redman, "An Emergency Management Doctrine," Preprints (2021) https://doi.org/10.20944/preprints202102.0367.v1; Ministers Responsible for Emergency Management, An Emergency Management Framework for Canada, $3^{\text {rd }}$ Edition (Ottawa: Public Safety Canada, 2017).

${ }^{39}$ Alberta Government, "Alberta's Pandemic Influenza Plan," (2014) https://open.alberta.ca/dataset/c89245b6a7fc-4c24-be87-c2686341ffb5/resource/a652811e-42f2-4c0d-90af-54e0e759e05e/download/2014-albertaspandemic-influenza-plan-apip-march-2014.pdf.

${ }^{40}$ Meghan A Baker, et al., "Low risk of coronavirus disease 2019 (COVID-19) among patients exposed to infected healthcare workers," Clinical Infectious Diseases, (2020) https://doi.org/10.1093/cid/ciaa1269.

${ }^{41}$ Jude Bayham, Eli P Fenichel, "Impact of school closures for COVID-19 on the US health-care workforce and net mortality: a modelling study," Lancet Public Health (2020) 5(5): E271-E278; Howard Lempel, Joshua M Epstein, Ross A Hammond, "Economic cost and health care workforce effects of school closures in the U.S.," PLOS Currents Influenza (2009) https://doi.org/10.1371/currents.RRN1051. 
Well-planned voluntary re-deployment of retired and less-busy healthcare workers, and rapid on-thejob training of more senior student nurses and medical students would also help.

Third, the focus of response should not be based on fear. Governments should educate the public on the difficult trade-offs, real risks from SARS-CoV-2, and collateral damage lockdowns cause. With a focus on protecting people at high-risk of adverse outcomes, ensuring the medical system is robust to manage people with COVID-19, and informing the public its government knows how to deal with the situation, the shift to confidence will mitigate the societal disruption and adverse economic impacts.

Fourth, now that safe and effective vaccines are available, providing vaccines to those at highest risk can further increase their protection (and obviate requiring their separation from the virus threat), reduce healthcare surge demands, and reduce fear, without population-wide lockdowns.

Thus, we argue that protecting people most at risk from illness and hospitalization can be done without shutting down all of society, that shifting from fear to confidence in the response (although difficult) is possible and will further mitigate societal disruption and economic devastation, and that safe and effective vaccines for those at highest risk will contribute to protection, minimize healthcare surge capacity requirements, and improve confidence.

(PL4) Both reducing case rates and death rates must be the goal.

Readers likely recognized that we assumed this premise was false in suggesting the focused protection response based on EM principles. This response focuses on protecting those most vulnerable to adverse outcomes, while allowing the case rates in other age groups to be high. We believe that we refuted (PL4) in our discussion of "no one is protected until everyone is protected" above. To review the main points, the infection fatality rate is very low in children $<20$ years (up to $0.003 \%$ in systematic reviews), and increases with age; but, even at age $55-59$ years is about $0.32 \%$. The infection fatality rate in those $<50$ years in Canada (likely $<0.013 \%$ ) was lower than for influenza in the USA (up to $0.016 \%$ in those 20 49 years in 2018-19). The median infection fatality rate of COVID-19 in those age $\leq 70$ years of $0.05 \%$ is not much higher than that for influenza in those $<65$ years in the United States of $0.021 \%$ in $2018-19$. We also believe we refuted (PL4) in the discussion above of "lockdowns will therefore have a favorable cost-benefit balance." To review the main points, many of the adverse effects of population-wide lockdowns fall on younger people who are at very low risk of death from COVID-19. These include the effects of school closures, intimate partner violence, deteriorating mental health, loneliness, unemployment, adverse childhood experiences, disrupted healthcare, worsened societal inequality, and disruption of the sustainable development goals in low- and middle-income countries. Reducing case rates in younger people should not be the focus of a reasoned response to the pandemic.

\section{Objections Considered}

\section{Objection 1: When refuting "lockdowns will therefore have a favorable cost-benefit balance", we were missing some assumed premises.}

Missing premises we can be criticized for assuming include:

(MP1) The economic recession can be attributed to lockdowns, and would not have occurred without lockdowns.

(MP2) Long-COVID patients with persistent symptoms will not change the cost-benefit balance against lockdowns. 
Rational Argumentation and Pandemic Response

(MP3) Healthcare capacity will not be overwhelmed if lockdowns are not used, or at least not enough to change the cost-benefit balance.

(MP4) Variants "of concern" that are more transmissible and lethal will not change the cost-benefit balance against lockdowns.

We will defend each premise in turn.

(MP1) The economic recession can be attributed to lockdowns, and would not have occurred without lockdowns.

The criticism makes the claim that without lockdowns people would still avoid businesses and therefore there would still be an economic recession in addition to all the deaths from no lockdowns. This seems very unlikely. Lockdowns involved direct commands to halt work, restrict travel, restrict the number of people inside dwellings and businesses, close factory floors, and stay-at-home. At the very least it is highly likely that the recession would have been much less severe without these orders. ${ }^{42}$ It is important to note that comparison of economic recession among countries is less informative on this point because, if many countries lockdown, in our globalized world of interconnected commerce with entangled webs of supply and demand even non-lockdown countries will be affected. Even so, it is interesting to note that non-lockdown Sweden is projected to have less gross domestic product loss in 2020 than the European average $(-2.9 \%$ vs. $-6.8 \%)$ and to be among the top three countries in the European outlook for 2021 and $2022 .{ }^{43}$

In addition, the criticism assumes other unstated premises. First, it is assumed that no other response would occur if lockdowns were not implemented; however, we have refuted that claim above in the discussion of "lockdowns are the only highly effective way to prevent the spread of SARS-CoV-2." Second, it is assumed that fear and anxiety would be what keeps people at home even if there were no imposed lockdowns. We believe this is related to the assumption that no other response would occur. In our discussion of a better response using EM principles, we stressed that the message to the public must shift from fear to confidence, and that this can be done using EM principles. It is interesting that many official bodies have come to the consensus that the lockdowns are largely responsible for the recession. ${ }^{44}$

\footnotetext{
${ }^{42}$ International Monetary Fund, World economic outlook: a long and difficult ascent (Washington: International Monetary Fund, 2020). https://www.imf.org/en/Publications/WEO/Issues/2020/09/30/world-economic-outlookoctober-2020

${ }^{43}$ European Commission's Directorate-General for Economic and Financial Affairs, European economic forecast. Winter 2021 (interim). Institutional Paper 144 (European Union, February 2021).

https://ec.europa.eu/info/sites/info/files/economy-finance/ip144 en 1.pdf

${ }^{44}$ Monetary Policy Committee, Bank of England May Monetary Policy Report (London: Bank of England, May 2020), pages 6-7 and Table 1A. https://www.bankofengland.co.uk/-/media/boe/files/monetary-policyreport/2020/may/monetary-policy-report-may2020\#: :text=The\%20Bank\%20of\%20England's\%20Monetary,to\%20sustain\%20growth\%20and\%20employment.\&t ext=At\%20its\%20meeting\%20ending\%20on,maintain\%20Bank\%20Rate\%20at\%200.1\%25; Reserve Bank of Australia, Statement on Monetary Policy - May 2020 6. Economic Outlook, (2020) https://www.rba.gov.au/publications/smp/2020/may/economic-outlook.html; OECD, Evaluating the Initial Impact of COVID-19 Containment Measures on Economic Activity, (2020) https://www.oecd.org/coronavirus/policyresponses/evaluating-the-initial-impact-of-covid-19-containment-measures-on-economic-activity-b1f6b68b/; Chief Public Health Officer of Canada, "Report on the State of Public Health in Canada 2020," page 29.
} 
(MP2) Long-COVID patients with persistent symptoms will not change the cost-benefit balance against lockdowns.

The criticism makes the claim that long-COVID will be so prevalent and severe that lockdowns are required to prevent all infections. We believe we have defended this premise above in our discussion of "no one is protected until everyone is protected." To review some main points, the incidence, severity, and duration of long-COVID are not known; a very generous figure is that up to $2.3 \%$ having COVID-19 may have symptoms lasting $\geq 12$ weeks; many of the cases might be attributable to the loneliness, anxiety, and depression of social isolation and unemployment; and other cases might be attributable to the negative expectations (nocebo effects) induced by the anxiety and fear inherent in reports from the press and social media. Overall, the incidence, severity, and duration of long-COVID would need to be implausibly high to change the cost-benefit balance to favor lockdowns. ${ }^{45}$

(MP3) Healthcare capacity will not be overwhelmed if lockdowns are not used, or at least not enough to change the cost-benefit balance.

The criticism makes the claim that healthcare capacity will be overwhelmed, causing many unnecessary deaths that lockdowns would have prevented. This critique was discussed and defended above when considering "no one is protected until everyone is protected" and "lockdowns are highly effective at preventing the spread of SARS-CoV-2." Here we will take a different tactic to defend (MP3). We believe that the criticism is based on several implied but false premises.

First is the premise that preserving healthcare capacity from being overrun is the goal of the response. However, we argued above that a better goal is to prevent the most harm to society as a whole. Of course, that includes attempting to preserve healthcare capacity, but does not aim solely at that goal. The magnitude of overwhelmed healthcare capacity would need to be remarkably high to change the cost-benefit balance in favor of lockdowns, assuming lockdowns are highly effective. Second is the premise that lockdowns are the only way to preserve healthcare capacity. However, we argued above that there is a better response option, based on EM principles, that can largely preserve healthcare capacity by protecting those older people at highest risk, and ensuring surge capacity and healthcare workforce. Finally, is the premise that it is not possible to develop surge capacity. This seems very unlikely. Surely increased capacity can be developed without shutting down other healthcare demands, and at far less cost than the government payments to lockdown-induced unemployed or unable to work people. Moreover, we suggest that there was ample time between the first and second waves of the pandemic to prepare healthcare surge capacity (without a plan to curtail other healthcare demands).

Thus, we argue that creating surge capacity for hospitals is feasible, without shutting down other healthcare needs.

(MP4) Variants "of concern" (VOC) that are more transmissible and lethal will not change the costbenefit balance against lockdowns.

The criticism would claim that VOC are more transmissible and lethal such that they require a harsher lockdown response. There are several unstated premises here that we believe are questionable. First, that VOC are more transmissible. ${ }^{46}$ This is based on mathematical modelling, and forecasting in this

\footnotetext{
${ }^{45}$ Lally, "Costs and Benefits in Australia."

${ }^{46}$ Nicholas G Davies, et al., "Estimated transmissibility and impact of SARS-CoV-2 lineage B.1.1.7 in England," Science 372, no. 6538 (2021): eabg3055; Erik Volz, et al., "Assessing transmissibility of SARS-CoV-2 lineage B.1.1.7 in England," Nature (2021) https://doi.org/10.1038/s41586-021-03470-x
} 
pandemic has repeatedly failed, making this suspect. ${ }^{47}$ Another study found that the course of the pandemic in the UK was not altered by the VOC B.1.1.7. ${ }^{48}$ Second, that VOC are more lethal. ${ }^{49}$ This is based on UK studies that used the same data on identified community cases, and had limitations, including that over $50 \%$ of cases were missing from the analysis, only $9 \%$ of deaths in the UK over the time period were included in the analysis, and the lack of adjustment for co-morbidities. Other studies find no increase in case fatality rate due to VOC B.1.1.7. ${ }^{50} \mathrm{Third}$, that lockdowns are highly effective at reducing transmission of the VOC. We already discussed that this is likely an exaggeration. Fourth, that lockdowns are the only response available. Again, we discussed this being false above; in fact, if VOC have the claimed $30-60 \%$ increase in case fatality rate, this will mean that EM principles are even more important to protect the most vulnerable in the population without the costs of lockdowns (as there is no difference in the relative increased risk by age). Fifth, that vaccine will not be effective (enough) for the VOC. The efficacy of current vaccines to prevent severe COVID-19 for the B.1.351 VOC is unknown; however, some data suggests that T-cell immune responses induced by the vaccine may still be capable of preventing severe COVID-19. ${ }^{51}$ Emerging evidence suggests that current mRNA and other vaccines are highly effective at preventing severe disease from COVID-19 even for the B.1.351 VOC. ${ }^{52}$ Moreover, if vaccines are not effective for a future VOC, this will make EM principles even more important.

\section{Objection 2: How can so many be wrong about imposing lockdowns during this pandemic?}

This objection implies that something in our arguments must be wrong or misrepresented, because if it were so obvious there would not be so many countries imposing lockdowns to "flatten the curve". We have attempted to defend each of our arguments with evidence, and believe this evidence has not been misrepresented. Nevertheless, it is reasonable to ask how we might explain that so many people all over the world did not do as we suggest, that is, develop an informed EM response to the pandemic that did not include population-wide lockdowns. There are several potential explanations for this phenomenon.

First, there are several cognitive biases deeply rooted in human psychology that impeded consideration of some of the points we have discussed. ${ }^{53}$ These biases include identifiable victim bias (hidden

\footnotetext{
${ }^{47}$ Ioannidis, Cripps, and Tanner, "Forecasting."

${ }^{48}$ Ellis D, et al., "The course of the UK COVID-19 pandemic; no measurable impact of new variants," medRxiv (2021) https://doi.org/10.1101/2021.03.16.21253534.

${ }^{49}$ Nicholas G Davies, et al., "Increased mortality in community-tested cases of SARS-CoV-2 lineage B.1.1.7," Nature (2021) https://doi.org/10.1038/s41586-021-03426-1; Robert Challen, et al., "Risk of mortality in patients infected with SARS-CoV-2 variant of concern 202012/1: matched cohort study," British Medical Journal, 372 (2021): n579.

${ }^{50}$ Sean Wei Xiang Ong, Barnaby Edward Young, David Chien Lye. "Lack of detail in population-level data impedes analysis of SARS-CoV-2 variants of concern and clinical outcomes," Lancet Infectious Diseases (2021)

https://doi.org/10.1016/S1473-3099(21)00201-2; Dan Frampton, et al., "Genomic characteristics and clinical effect of the emergent SARS-CoV-2 B.1.1.7 lineage in London, UK: a whole-genome sequencing and hospital-based cohort study," Lancet Infectious Diseases (2021) https://doi.org/10.1016/S1473-3099(21)00170-5; Andrew Atkeson, "A parsimonious behavioral SEIR model of the 2020 COVID epidemic in the United States and the United Kingdom," NBER Working Paper Series (Feb 2021) https://doi.org/10.3386/w28434.

${ }^{51}$ Daniel M Altmann, Rosemary J Boyton, and Rupert Beale, "Immunity to SARS-CoV-2 variants of concern," Science 371, no. 6534 (2021): 1103-1104.

52 Ewen Callaway, "Pfizer COVID vaccine protects against worrying Coronavirus variants," Nature (2021) https://doi.org/10.1038/d41586-021-01222-5; Vivek Shindle, et al., "Efficacy of NVX-CoV2373 Covid-19 vaccine against the B.1.351 variant. NEJM (2021) https://doi.org/10.1056/NEJMoa2103055; Laith J Abu-Raddad, et al., "Effectiveness of the BNT162b2 Covid-19 vaccine against the B.1.1.7 and B.1.351 variants," NEJM (2021) https://doi.org/10.1056/NEJMc2104974.

${ }^{53}$ Scott D Halpern, Robert D Truog, and Franklin G Miller, "Cognitive bias and public health policy during the COVID-19 pandemic," Journal of the American Medical Association, 324 (2020): 337-338; Benjamin Brooks, et al.,
} 
"statistical lives" are easily ignored), present bias (immediate benefits are preferred to even larger future benefits), availability bias (vividness of COVID-19 deaths captured attention), anchoring bias (we often disregard evidence that might disprove our own theory), escalation of commitment bias (we invest more and more resources into our set course of action instead of realizing losses), and prominence effect (we simplify complex tradeoffs by focusing on a prominent objective (e.g., security), and choose so as to obtain this, while non-prominent aspects are neglected). Second, there is a phenomenon sometimes called "crowd effects." Charles Mackay wrote in his book "Extraordinary popular delusions and the madness of crowds": "Truth, when discovered, comes upon most of us like an intruder, and meets the intruder's welcome;" and "Men, it has been well said, think in herds; it will be seen that they go mad in herds, while they only recover their senses slowly, and one by one." ${ }^{54}$ Paul Frijters has described that we became united in crowds, acting together against a common threat, in a war against an invisible enemy that will be won, with a "disregard and disinterest on the part of individuals in the enormity of the collateral damage, either to their own kids, people in other countries, their own futures...." ${ }^{55}$ The parasite hypothesis, supported by evidence, finds that the "subjective perception of infection risk causes individuals to be more conformist, to prefer conformity and obedience in others, [and] to respond more negatively toward others who fail to conform...." ${ }^{56}$ These crowd effects may be considered a type of contagious mass hysteria, associated with fear, anxiety, and panic perpetuated by the media. ${ }^{57}$ Third, there is the phenomenon of "groupthink", which is the tendency of groups to let the desire for harmony and conformity prevail, which can lead to poor decision-making and escalation of commitment. ${ }^{58}$ In this regard, it is interesting to note that lockdowns spread to about $80 \%$ of OECD countries within a two-week period in March 2020, and the main predictor of a country implementing lockdowns was the number of earlier adopters in the same region. ${ }^{59}$

\section{Objection 3: The number of deaths from COVID-19 without lockdowns will be so high that fear and panic will occur and destabilize society.}

We believe we have addressed and refuted this concern when we discussed the flawed premises involved in the assertion that "population lockdowns are required to protect those at high risk of adverse outcomes." In addition, there does not seem to have been reports of society destabilization in non-lockdown states (e.g., Florida, South Dakota) or countries (e.g., Sweden, Taiwan). Nevertheless, there is some truth to this objection in that any approach to the pandemic must start by controlling the fear and panic and shifting to confidence. This will be difficult. We discussed this above in the section "(PL3) lockdowns are the only highly effective way to prevent the spread of SARS-CoV-2, reducing case and death rates." To repeat ourselves, there we wrote that governments should educate the public on

\footnotetext{
"Managing cognitive biases during disaster response: the development of an aide memoire," Cognition, Technology \& Work, 22 (2020): 249-61; Paul Slovic, "Risk perception and risk analysis in a hyperpartisan and virtuously violent world," Risk Analysis, 40, Supplement 1 (2020): 2231-2239.

${ }^{54}$ Charles Mackay, Extraordinary Popular Delusions and The Madness of Crowds (Petersfield, Hampshire: Harriman House Ltd, 2003).

${ }^{55}$ Paul Frijters, "What Kind of Crowd Are We Now Seeing? The 5 Surprises in This Pandemic," Club Troppo (2020) https://clubtroppo.com.au/2020/06/17/what-kind-of-crowd-are-we-now-seeing-the-5-surprises-in-thispandemic/.

${ }^{56}$ Damian R Murray, Mark Schaller, and Peter Suedfeld, "Pathogens and politics: Further evidence that parasite prevalence predicts authoritarianism," PLoS One, 8, no. 5 (2013): e62275.

${ }^{57}$ Bagus, Pena-Ramos, and Sanchez-Bayon A, "COVID-19 and the political economy," 1376.

58 Joffe, "Rethinking," 625778.

${ }^{59}$ Sebhatu et al., "Explaining the homogeneous diffusion," 21201-21208.
} 
the trade-offs, the real risks from SARS-CoV-2, and the collateral damage lockdowns cause. ${ }^{60}$ This can start with a focus on protecting people at high-risk of adverse outcomes, ensuring the medical system is robust to manage people with COVID-19, and informing the public its government knows how to deal with the situation.

\section{Objection 4: This is age discrimination.}

The objection would claim that singling out the elderly as at high risk and therefore being subject to lockdown in the EM response amounts to age discrimination. Moreover, using years of life lost as a metric in cost-benefit analysis also penalizes older people, and again amounts to age discrimination. The objection fails on two counts.

First, pointing out that the truly high-risk group is older people only emphasizes that this is the group that requires protection; from that, we can evaluate the best way to provide that protection, which turns out to be voluntary quarantine of older people. Prolonged quarantine of all groups is what has occurred now, and based on cost-benefit analysis this is what is unethical by causing far more harm to all, including the high-risk elderly. We can minimize the harm to all of society by protecting the vulnerable with their voluntary quarantine, and protecting the rest of society from harm by allowing their ongoing activity.

Second, as Peter Singer has pointed out, "what medical treatment does, if successful, is prolong lives. Successfully treating a disease that kills children and young adults is, other things being equal, likely to lead to a greater prolongation, and thus do more good, than successfully treating a disease that kills people in the 70 's, 80 's, and $90^{\prime} \mathrm{s.}^{\prime \prime 1}$ When we try to stay healthy "what we are trying to do is to live as long as we can, compatibly with having a positive quality of life for the years that remain to us. If life is a good, then, other things being equal, it is better to have more of it rather than less." 62 It follows that we should count every quality adjusted life year equally, whether it is in the life of a teenager or a 90-year old. ${ }^{63}$ This was the conclusion of "The Fair Priority Model" for global vaccine allocation, where priority was given to preventing premature death by using an expected years of life lost metric. ${ }^{64}$ Martin Lally has put this point as follows, that not considering quality adjusted life years equally "implies that one would spend as much to extend the life of a person by one day (or even one hour) as one would spend to extend the life of a different person for fifty years... [If this] interpretation is correct, it would be perverse to do so. It would also be inconsistent with prevailing views amongst public health experts in Australia and elsewhere, in which the impact of health interventions on the residual life expectancy of the targets is estimated and converted to a monetary figure using a value per year." ${ }^{65}$

\footnotetext{
60 Peter M Sandman, and Jody Lanard, "COVID-19: The CIDRAP (Center for Infectious Disease Research and Policy, University of Minnesota) Viewpoint. Part 2: Effective COVID-19 Crisis Communication," (2020)

https://www.cidrap.umn.edu/sites/default/files/public/downloads/cidrap-covid19-viewpoint-part2.pdf.

${ }^{61}$ Peter Singer, "Is age discrimination acceptable?," Project Syndicate (June 10, 2020). https://www.projectsyndicate.org/commentary/when-is-age-discrimination-acceptable-by-peter-singer-2020-06?barrier=accesspaylog.

${ }^{62}$ Singer, "age discrimination"

${ }^{63}$ Singer, "Age discrimination"; Peter Singer P, and Lucy Winkett, "The duel: is it more important to save younger lives," Prospect (May 4, 2020). https://www.prospectmagazine.co.uk/magazine/the-duel-is-it-more-important-tosave-younger-lives-peter-singer-debate-coronavirus-medicine-ethics-philosophy.

${ }^{64}$ Ezekiel J Emanuel, et al., "An ethical framework for global vaccine allocation," Science 369, no. 6509 (2020): 1309-1311.

${ }^{65}$ Lally, "Costs and Benefits in Australia," page 25.
} 
To further make the point that this is not age discrimination, one can compare racism to prioritizing weighted years of life lost. In discrimination such as racism, where "no one who is black was ever white [and vice-versa]," we must take an impartial perspective from which we can see that it is in everyone's interests to save lives regardless of race. In the current case, where "everyone who is old was once young," there is also an impartial perspective from which we can see that it is in everyone's interests to save the lives of younger people. ${ }^{66}$ In a thought-experiment, Peter Singer asks us to imagine that you have just become a parent, that at some stage in your child's life she is likely to be infected with a dangerous virus, and that her chances of being infected and dying from the infection are the same in any year of her life. He then asks us to imagine that curative drug $A$, effective if $<40$ years old, and drug $B$, effective if $>40$ years old, are so costly that the government cannot afford both to be produced. Which drug should be produced? It is clearly contrary to your child's interests to vote for drug B - this would increase her risk of dying before her $40^{\text {th }}$ birthday; we vote for drug $\mathrm{A}$ in order to improve her chances of living a longer life. ${ }^{67}$

One way to take an impartial perspective is to empirically aim to use veil-of-ignorance reasoning to adjudicate claims of fairness. In this setting, a fair distribution of resources is said to be that which people would choose out of self-interest, without knowing whom among those affected they will be. In an experimental study, participants were asked to decide whether to give the last available ventilator in their hospital to the 65-year-old who arrived first (already being "prepped for the ventilator"), or the 25year-old who arrived moments later, assuming whoever is saved will live to age 80 years. In the veil-ofignorance condition the participants were asked to "imagine that you have a $50 \%$ chance of being the older patient, and $50 \%$ the younger." When asked if "it is morally acceptable to give the last ventilator to the younger patient", $66 \%$ in the veil-of-ignorance condition vs. $53 \%$ in the control condition answered 'yes' (odds ratio $1.69 ; 95 \% \mathrm{Cl} 1.12,2.57)$; compared to younger participants (18-30 years), older participants (odds ratio 3.98) and middle-aged participants (odds ratio 2.02) were more likely to shift their response to agree. In the veil-of-ignorance condition, asked if "you want the doctor to give the ventilator to the younger patient", $77 \%$ answered yes, therefore maximizing the number of life-years saved rather than the number of lives saved. ${ }^{68}$

\section{Objection 5: The goal should be COVID-Zero.}

The objection claims that the experience of Australia, Iceland, Japan, New Zealand, and South Korea, and sometimes also Taiwan, Singapore, and Hong Kong, suggests that aiming for zero COVID-19 cases should be the goal. ${ }^{69}$ Since these countries have relatively low case and death rates from COVID-19, and have had the ability to somewhat open their society, the argument concludes that all countries should similarly have this goal of achieving zero-COVID. This argument contains several assumed premises that fail critical scrutiny.

First, again there is the assumption that low case and death rates were causally due to swift and harsh lockdowns implemented for long enough to suppress transmission, and thus elimination is achievable elsewhere. We refuted this claim above when discussing "Lockdowns are highly effective at preventing

\footnotetext{
${ }^{66}$ Singer and Winkett, "The duel."

67 Singer and Winkett, "The duel."

${ }^{68}$ Karen Huang, et al., "Veil-of-Ignorance reasoning favors allocating resources to younger patients during the COVID-19 crisis," PsyArXiv (May 27, 2020) https://psyarxiv.com/npm4v/.

${ }^{69}$ Miquel Oliu-Barton, et al., "SARS-CoV-2 elimination, not mitigation, creates best outcomes for health, the economy, and civil liberties," Lancet (2021) https://doi.org/10.1016/S0140-6736(21)00978-8.
} 
the spread of SARS-CoV-2." Interestingly, these countries had lower (and variable) severity of population lockdowns than most other countries, and their "success" was almost certainly due to other factors. Some factors may include the East-Asian culture of mask wearing and not shaking hands, possible higher pre-existing cross-immunity, seasonality, and, most importantly, that these countries are islands that could therefore strictly close their international borders (that do not have essential land-based supply chains). ${ }^{70}$ Other counties, provinces, and countries cannot choose to be islands.

Second is the assumption that, even if achievable (by what would be very prolonged lockdowns for countries where there are already many thousands of SARS-CoV-2 infections), the cost-benefit ratio of achieving zero-COVID is favorable. We refuted this claim above when discussing "Lockdowns will therefore have a favorable cost-benefit balance." Cost-benefit analyses in Australia and New Zealand find that the balance has been very far from favorable to lockdowns. ${ }^{71}$ The Institute of Public Affairs in Australia wrote that elimination is "indulgent utopian theorizing by a small group of elites who are divorced from the lived experience of mainstream Australians... [it] means zero jobs, zero freedom, and zero hope." 72

Third is the assumption that there is an exit strategy from zero-COVID. Oliu-Barton et al. wrote that "countries that opt to live with the virus will likely pose a threat to other countries [that adopt zeroCOVID]," aptly (and ominously) describing the problem. ${ }^{73}$ These countries closed borders only to find themselves sequestered from "a world where the virus is endemic and will remain so for the foreseeable future." ${ }^{\prime 4}$ They face the continual and unpredictable threat of sudden lockdown for any sporadic breakthrough cases. ${ }^{75}$ One potential exit strategy from border closures would be to achieve herd immunity from extensive population vaccination. But vaccine immunity is not lifelong (as demonstrated by natural immunity not being so) and would require repeated booster vaccines, no vaccine is yet proven safe for children, there are limited vaccine supplies and poor vaccine uptake, and there is the possibility of future variants that evade vaccine. ${ }^{76}$ The zero-tolerance due to fear, sunk-cost bias (not wanting to face that previous efforts have been wasted), and loss-aversion (caring more about avoiding losses from COVID than about gains from living with the virus), have painted these countries into a corner, being unwilling to accept any risk of letting the SARS-CoV- 2 in. ${ }^{77}$

\footnotetext{
${ }^{70}$ Lally, "Costs and Benefits in Australia"; Allen, "Covid lockdown cost/benefits"; Ramesh Thakur, "Covid and culture cringe: Data tell us all we need to know about tackling the virus," Features Australia (2020) https://www.spectator.com.au/2020/11/covid-and-culture-cringe/.

${ }^{71}$ Lally, "Costs and Benefits in Australia"; Foster, "Cost-Benefit Analysis Executive Summary"; Heatley, "Cost Benefit Analysis of 5 Extra Days"; Martin Lally, "The costs and benefits of COVID-19 lockdowns," (Nov 2020) https://nzfc.ac.nz/papers/updated/53.pdf.

${ }^{72}$ Asher Judah, Daniel Wild, "Medical capacity: an alternative to lockdowns," Institute of Public Affairs (30 Sept 2020) https://apo.org.au/node/308804.

${ }^{73}$ Judah and Wild, "Medical capacity."

${ }^{74}$ Health Advisory \& Recovery Team, "COVID-19: An overview of the evidence," Australia (2021) https://www.hartgroup.org/covid-19-evidence/ (page 18).

${ }^{75}$ Gabriel Scally, Sunetra Gupta, "The duel: Is eliminating Covid-19 worth it?," Prospect Magazine (2021) https://www.prospectmagazine.co.uk/the-duel/duel-eliminating-covid-19-lockdowns-gabriel-scally-sunetra-gupta; ${ }^{76}$ Scally and Gupta, "The duel"; John Power, "As West races back to travel, 'zero-Covid' economies like Hong Kong, Singapore and Australia face hermit risk," South China Morning Post (May 2021) https://www.scmp.com/weekasia/health-environment/article/3132633/west-races-back-travel-zero-covid-economies-hong-kong;

77 Donald Low, "In chasing zero Covid-19 infections, Hong Kong, Singapore, Australia and others have become trapped by their own success," South China Morning Post (May 2021) https://www.scmp.com/weekasia/opinion/article/3132638/chasing-zero-covid-19-infections-hong-kong-singapore-australia.
} 
The most likely pandemic outcome is that SARS-CoV-2 will be an endemic virus, similar to other seasonal Coronaviruses. ${ }^{78}$ Once initial herd immunity is achieved through natural infections in the least vulnerable, and vaccines in the most vulnerable, there will be high protection from severe COVID-19. At that point, maintenance of herd immunity may be established through natural infections, with first infections occurring mostly in children who have a very low risk (lower than from seasonal Influenza viruses) of adverse outcomes. Until then, emergency management principles remain the best approach, lockdowns remain a misguided and very costly approach, and elimination remains impossible.

\section{Objection 6: What if we are wrong?}

We admit that any empirical data is open to change as more data accumulates. It is possible that more data will find some of our arguments to be based on inaccurate premises. It is possible that a new variant will emerge that causes markedly more severe outcomes to younger people. To this we respond with a few points. First, given all the collateral damage effects discussed above, it is unlikely the costbenefit balance would shift to favor lockdowns. Second, this is even more unlikely when using EM principles. Part of EM is to continuously re-evaluate the information available from a diverse group of experts, and modify responses as necessary. Third, with the vaccines becoming available the risk to all population groups will likely keep falling as more can be vaccinated over time. If new vaccines for new variants become needed, the now established platforms used for vaccine production may be quickly used to develop modified vaccines.

\section{What has not been discussed here.}

It is worth pointing out what debates we have not engaged in here. First, we make no comment on the need for community mask use. Although the evidence for the use of masks to prevent transmission of SARS-CoV-2 in the community is of low quality at best, we are not making any anti-masking argument. ${ }^{79}$ Second, we strongly support the widespread use of currently licensed vaccines for those at high risk of adverse outcomes from SARS-CoV-2. Although ongoing post-marketing studies will clarify any potential longer-term risks from vaccines, we are not making any anti-vaccine argument. Third, we do not engage with the debate on diagnostic polymerase chain reaction (PCR) testing thresholds. We acknowledge that if the test is too sensitive (i.e., a diagnosis being made at high cycle threshold) this can misinform individual isolation decisions (i.e., viable virus is likely no longer present at higher cycle thresholds). ${ }^{80}$ We also acknowledge that the specificity of the test is not $100 \%$, with a non-zero, likely $<1 \%$ false positive rate particularly at higher cycle thresholds, which in contact-tracing studies can result in an overestimated risk of asymptomatic transmission (upon which much of the theory of lockdowns is based). ${ }^{81}$ We are not making any anti-PCR testing argument. Fourth, we are saddened by the immense morbidity and mortality caused by this virus, and do not in any way wish to minimize the importance of this. We

\footnotetext{
${ }^{78}$ Stephen M Kissler, et al., "Projecting the transmission dynamics of SARS-CoV-2 through the postpandemic period," Science (2020) 368(6493):860-868.

${ }^{79}$ Roger Chou, et al., "Update Alert 5: Masks for prevention of respiratory virus infections, including SARS-CoV-2, in health care and community settings: a living rapid review," Annals of Internal Medicine (2021)

https://doi.org/10.7326/L21-0116

${ }^{80}$ Muge Cevik, et al., "SARS-CoV-2, SARS-CoV, and MERS-CoV viral load dynamics, duration of viral shedding, and infectiousness: a systematic review and meta-analysis," Lancet Microbe, 2 (2021) :e13-22.

${ }^{81}$ Clare Craig, and Jonathan Engler, "Has the evidence of asymptomatic spread of COVID-19 been significantly overstate?," Lockdown Sceptics (March 7, 2021) https://lockdownsceptics.org/has-the-evidence-of-asymptomaticspread-of-covid-19-been-significantly-overstated-2/.
} 
are aiming to infer, based on argument, the best response to this tragedy in order to minimize the impact on all of us, now and into the future.

\section{Conclusions}

We have subjected the conclusions (made during the SARS-CoV-2 pandemic) that "no one is protected until everyone is protected" and "population lockdowns are required to protect those at high risk of adverse outcomes" to critical scrutiny. We find these conclusions are based on premises that can be refuted. While this does not definitely disprove the conclusions, it shows that the best premises we believe are on offer to support the conclusions are false. However, we did gesture at a better conclusion that we explicitly state here:

(C) An EM principles based response to the pandemic, compared to population-wide lockdowns, offers a way to prevent more adverse outcomes from COVID-19, better prevent overwhelmed healthcare, and prevent most of the collateral damage to the wellbeing of the population that has resulted from the lockdowns.

This is based on several premises, the evidence for which we have discussed above.

(P1) Older people in the population, particularly those with co-morbidities, are those who are at high risk of adverse outcomes from SARS-CoV-2 infection.

(P2) Protecting these people from illness and hospitalization can be done, without shutting down all of society.

(P3) Creating surge capacity for hospitals is feasible, without shutting down other healthcare needs.

(P4) Shifting from fear to confidence in the response, although difficult, is possible, and will further mitigate societal disruption and economic devastation.

(P5) Safe and effective vaccines for those at highest risk contribute to protection, minimize surge healthcare capacity requirements, and improve confidence.

We hope for this alternative response. 